\title{
Peer Collaborative Interactions: Implications for Enhancing Creativity and Innovation among Learners in Cameroon.
}

\author{
Dr. Kumncho Eveline Neh* \\ Department of Educational Psychology, Faculty of Education, University of Buea, Cameroon
}

*Corresponding Authors: Dr. Kumncho Eveline Neh, Department of Educational Psychology, Faculty of Education, University of Buea, Cameroon

\begin{abstract}
Since the emergence of a global movement that calls for a new model of learning for the twentyfirst century, it has been argued that formal education must be transformed to enable new forms of learning that are needed to tackle complex global challenges. Literature on this topic offers compelling arguments for transforming pedagogy to better support acquisition of twenty-first century skills. However, the question of how best to teach these skills is largely overlooked. Experts recognize that the 'transmission' or lecture model is highly ineffective for teaching twenty-first century competencies and skills, yet widespread use of this model continues. In spite of worldwide agreement that learners need skills such as critical thinking and the ability to communicate effectively, innovate, and solve problems through negotiation and collaboration, pedagogy has seldom adapted to address these challenges. Rethinking peer collaborative interactions for the twenty-first century is as crucial as identifying the new competencies that today's learners need to develop. This article, dwells on the Futures of Learning, explores pedagogies and learning environments that may contribute to the development and mastery of twenty-first century competencies and skills, and advance the quality of learning. Rethinking peer collaborative interactions for the twenty-first century is as crucial as identifying the new competencies that today's learners need to develop. Traditional approaches emphasizing memorization or the application of simple procedures will not advance learners' critical thinking skills or autonomy. To develop the higher-order skills they now need, individuals must engage in meaningful enquiry-based learning that has genuine value and relevance for them personally and their communities. Real-world experiences merged with sustained engagement and collaboration offer opportunities for learners to construct and organize knowledge; engage in detailed research, enquiry, writing and analysis; and communicate effectively to audiences. This article therefore set a policy framework for all stakeholders involved in the education of learners in Cameroon.
\end{abstract}

Keywords: Peer Collaborative Interactions: Creativity and Innovation.

\section{INTRODUCTION}

The purpose of this study was to examine peer teaching in preschool peer group interactions in order to better understand the significance of these teaching experiences. Though many researchers have theorized about the process of children attaining knowledge from peers and the connection between cognitive development and social interaction, we do not know enough about what peer teaching looks like and the potential benefits of peer teaching through collaborative interactions. The constructs of the interactions in terms of verbal and non-verbal communication were analyzed to exhibit various teaching behaviors such as scaffolding and modeling based on the theory of L.S. Vygotsky. Vygotsky stated that learning awakens in children a variety of internal developmental processes that can operate only when they interact with more competent people in their environment and in cooperation with their peers (Vygotsky, 1978). He stressed that children develop in a social matrix that is formed by their relationships and interactions with other children. The social environment is a major contributor to the cognition of children because of the open area of communication that exists that allows them to express and negotiate ideas as well as contribute to each other's understanding. Vygotsky theorized that when children scaffold each other, they modify a task and offer assistance to each other to help complete the task (Tharpe \& Gallimore, 1988). When children model each other, they offer behaviors to each other for imitation, thereby helping each other to see the appropriate behaviors, understand the reasons for their use, and exhibit the specific behaviors in order to put them into their own understanding (Tharpe \& Gallimore, 1988). Scaffolding and modeling typically occur between children of different levels of cognitive and/or social understanding, though it is possible for it to 
occur between children of the same competence level. The premise behind these actions is that one child will teach another. One child will be more capable of completing a task than another, and will assist a peer in understanding and completing the specific process $\backslash$ at hand. A more-capable peer can also build on the competency of a less-capable peer and support a level of competence that is slightly beyond it. This behavior awakens developmental processes in children that can operate only when they interact with others in their environment and in cooperation with their peers (Miller, 1993).

\section{Cultivate Creativity and InNOvation}

Innovation and creativity are very valuable competencies in knowledge societies. Yet one question remains - do educators have the courage to disrupt conventional wisdom and encourage learners to improvise and pursue innovations that matter the most? In today's economy, innovations emerge from improvisational teams (Sawyer, 2006). Creativity is deeply social, with most creative insights typically emerging from collaborative and creative circles. Few schools teach students to create knowledge; instead learners are taught that knowledge is static and complete, and they become experts at consuming knowledge rather than producing it. McLoughlin and Lee (2008a) argue however that the ultimate goal of learning is to stimulate learners' capacities to create and generate ideas, concepts and knowledge. To this end, there is a need for meaningful learning experiences that tap into and expand learners' creativity, not extinguish it (Robinson, 2006). Teachers can play a key role by encouraging, identifying and fostering creativity (Saavedra and Opfer, 2012, Encouragement helps students to recognize and develop creative capacities in themselves that they might otherwise overlook. And as with metacognition, teaching about the creative process and what inspires or suppresses it contributes to creative development.

Cultivating creativity and innovation also demands that learning environments be transformed to support such growth. According to Sawyer (2008), environments that prepare learners for a knowledge intensive society will look very different from the standard model. The standard learning model, Learning 1.0, evolved in the early part of the twentieth century and incorporates the aspects of schooling generally considered 'normal and proper: students divided by grades, lessons by subjects, tests at the end of the year, and high school units collected until graduation' (Kerchner, 2011). In this model, schooling and most other forms of formal learning are built on the principle of acquisition and storage of information with a view to analysing and eventually using it. 'Pedagogy becomes the means to transfer knowledge through known and authoritative channels'. Traditional roles prevail in other words, teachers teach and students learn.

This model has outgrown its usefulness. Kerchner (2011) argues that Learning 2.0 is a very different proposition, consisting of a more flexible, personalized and experiential form of learning. $\mathrm{He}$ attributes the inspiration for this model in part to the network-based technologies that underpin the internet, but mainly to recent changes in how people think about learning. Learning 2.0 draws several elements from emerging learning innovations and the rapidly growing research literature on learning, technology and open education. These include:

- A mix of acquisition and practice of project-based learning and other immersive pedagogies;

- Individual education plans for all;

- The realization that learners, not only teachers, are the workers in the education system;

- The unbundling of teaching, learning and the assessment of competence; and

- The inclusion of essential twenty-first century skills such as learning how to solve difficult, ill-defined problems and learning how to collaborate).

Redecker et al. (2009) contend that the greatest potential for Learning 2.0 lies in its capacity to facilitate pedagogical innovation (i.e. transforming learning and teaching approaches to better address and achieve learning goals). Specifically, Learning 2.0 approaches can inspire:

- New ways of collaborating;

- The creation and exchange of new learning content and meta-data;

- New ways to communicate among learners and teachers/trainers; 
- More personalized and learner-centered environments;

- New forms of blended learning approaches (formal/ informal, classroom/distance, intra/extrainstitutional and mixed learning);

- New ways to document learner's competencies (e.g. e-portfolios, personal learning plans and learning diaries); and

- New motivations through the use of active, discovery based learning approaches, and learners' increased ownership of content (pp. 39-40).

\section{EMPLOY APPROPRIATE LEARNING TOOLS}

The transformation of pedagogy goes beyond the idea that new technologies will produce new forms of learning and new competencies. While technological developments play an important role in learning and can create new and unprecedented opportunities, technology alone cannot ensure a successful learning experience (Davies, Fidler and Gorbis, 2011). There are many different instructional tools available to teachers to stimulate learning and help learners create new knowledge in collaboration with their peers.

\section{STRATEgic Questioning}

Questioning is an effective technique to engage learners. Asking probing questions can foster curiosity and teaching learners to ask questions gives them practical tools to decipher challenging content. Cornell University's Center for Teaching Excellence (2014b) notes that students who can ask insightful questions are more likely to be successful in school. While questioning is a means to measure what learners know or assess their understanding of specific concepts, effective open-ended questions that probe and elicit expanded thinking and processing of information can be instrumental in stimulating deeper learning. Divergent questions have multiple possible answers and encourage learners to be creative and share their insights. Asking appropriately challenging and engaging questions stimulates discussion and creative and critical thinking. Questions encourage learners to explore and redefine their understanding of key concepts.

\section{DeSign ReleVANT AND REAL-World LEARNing ACTIVITIES}

To ensure effectiveness, any curriculum must be relevant to the lives of students (Mansilla and Jackson, 2011; Perkins, cited in Saavedra and Opfer, 2012). Learning activities that are designed to connect student experiences to real-world problems will transform their focus. The Partnership for 21st Century Skills (P21, 2007b) echoes this point: 'when students realize the connection between what they are learning and realworld issues that matter to them, their motivation soars, and so does their learning' (p. 3). Students' experiences in school differ markedly from their lives outside school. The increasing likelihood of school becoming irrelevant to interests and issues that affect them is therefore of real concern. As Buckingham (2007) notes, bridging this gap will require more than superficial attempts to combine education and entertainment, or use of the latest technological devices. McLoughlin and Lee (2008a) stress that, above all, learning tasks should be authentic, personalized, experiential, learner-driven and designed, and enable the creation of content and innovative ideas by learners). More active learning, more relevant curricula, more real-world learning and better-trained teachers will improve the quality of education overall and increase student engagement (Redecker and Punie, 2010).

In a recent foresight study on the future of learning, Redecker and Punie (2013) found that 90 per cent of experts polled agreed that schools must increase efforts to open up to society and integrate real-life experiences into teaching practices (p. 9). The use of real-world contexts is a key component of twenty-first century learning and instruction. According to the Partnership for 21st Century Skills (P21, 2007b), research suggests that "when teachers create meaningful learning activities that focus on the resources, strategies and contexts that students will encounter in adult life, absenteeism rates fall, cooperation and communication grow, and critical thinking skills and academic performance improve'.

\section{TEACH METACOGNITIVE SKILlS}

Put simply, metacognition is 'thinking about one's thinking'. More precisely, it refers to the processes used to plan, monitor and evaluate one's understanding and performance. Metacognition reflects an 
individual's critical awareness of how they think and learn, and their assessment of themselves as a thinker and learner. Metacognition is not solely an intrinsic talent; it can be taught and cultivated. Teachers can cultivate a metacognitive culture that promotes greater learning by giving learners 'permission' to identify their confusion, asking them what they find confusing and acknowledging their difficulties, integrating reflection into credited course assignments, having instructors model metacognitive thinking in their teaching, and offering learners explicit instructions on how to think in a metacognitive fashion. For learners to use metacognition successfully, they must be taught explicitly about the concept and its language. As Weimer (2012) notes:

It is terribly important that in explicit and concerted ways we make students aware of themselves as learners. We must regularly ask, not only 'What are you learning?' but 'How are you learning?' We must confront them with the effectiveness (or ineffectiveness) of their approaches. We must offer alternatives and then challenge students to test the efficacy of those approaches.

This kind of explicit instruction will give learners a way to talk about their learning and thinking. Students can then compare strategies with their peers, and expand or replace existing learning strategies with new and more effective ones. This process will result in learners thinking about their learning becoming much more transparent. Ultimately, this will allow them to make more informed learning choices and strengthen their individual judgment and sense of autonomy.

\section{BUILD THE RIGHT RELATIONSHIPS FOR LEARNING}

Relationships for learning are gaining new importance in the twenty-first century. New learning experiences will be collaborative, project or problem-based, and supported by relationships that allow students to practice new competencies of collaboration and communication until they master these skills (RAND Corporation, 2012). Quality learning and teaching are grounded in powerful relationships built on mutual respect and trust. Learning often results from the way in which ideas are shared, including between the teacher and the student. Lead beater (2008) emphasizes that learners need relationships that will motivate them to learn (p. 15). Motivating someone generally requires building trust, confidence and capability; boosting aspirations and ambitions; setting achievable goals and structured challenges; and offering relevant rewards and recognition. Good teachers already have these motivational skills, but good motivators can also include other children, older peers, siblings, parents and other adults, such as teaching assistants and role models in the community.

Individuals learn best when they are supported by the right set of relationships that motivate, engage, care about and reward them. Such relationships offer them opportunities to actively participate in learning and co-create new knowledge. Relationships for learning truly recognize individuals. Recognition is critical to young people trying to establish their sense of identity. Often the disaffection that some young people feel for education can be explained by their search for recognition and reputation outside education, at its most extreme through involvement in drugs, crime, sex and gangs. Relationships for learning make people feel safe and cared for. Having others treat you with respect and dignity, and having someone attend to your needs, all matter. Care and support may come from peers, teachers, experts or community members. Providing care generally involves being attentive, sensitive, noticing or even anticipating when someone might be in need, being responsive, engaging with the person to understand what they need, and being respectful of them as a person (Leadbeater, 2008).

\section{INCLUDE EVERY LEARNER THROUGH TECHNOLOGY}

The quest for a new knowledge paradigm cannot be separated from the goal of inclusion and more equitable distribution of knowledge in societies. Accessibility remains a significant obstacle to inclusion. Equity demands more focused attention to groups of low-achievers often neglected in traditional education systems. Mobile devices have proven very useful in enhancing inclusion. For instance, they can help students with disabilities gain access to the curriculum via applications that make text more readable or read text aloud, increasing reading speed and comprehension for students with dyslexia (UNESCO, 2013a). Mobile technology also supports teachers in individualizing instruction to accommodate students' unique needs. Making learning responsive to individual differences, and empowering and enabling each and every student to engage in learning, will help to re-create excitement for learning. 
Ultimately, education must respond more flexibly to cultural diversity and changing labour market expectations (Gijsbers and van Schoonhoven, 2012). Without question, such a move makes sense in places such as Africa, where twenty times more people connect to the internet through mobile phones than through fixed-line computers. In Colombia, mobile devices are being used instead of traditional desktop or laptop computers to address an illiteracy crisis in rural areas. In 2012, the Colombian government purchased 250,000 mobile devices equipped with interactive educational software and delivered them to illiterate young people and adults. Other countries have similar, albeit still unrealized, plans to launch mobile learning projects in an effort to increase educational opportunities for people in underprivileged communities (UNESCO, 2012).

Inclusion is at the heart of personalized learning which readily acknowledges individual learning styles. This acknowledgement, in turn, produces more motivated and engaged learners. However, enabling environments need to be created. Educational environments must promote inclusion and provide support (Carneiro and Draxler, 2008). Inclusive education is based fundamentally on human rights and the transformation of educational systems - both formal and informal - into environments more responsive to the diversity of learners' needs. Personalized learning has the potential to be highly inclusive, but this process will not occur automatically. Learners with disabilities, disadvantaged persons, those who want to relearn, and those previously unable to benefit from traditional compulsory education must all have the opportunity to benefit. Social media applications can be used to integrate learning into a wider community by reaching out to people from other age groups and socio-cultural backgrounds (Redecker and Punie, 2010). Linking learners to experts, researchers and practitioners in specific fields of study will also open up alternative channels for gaining knowledge and enhancing skills.

\section{Highlight Learner-CENTRED ModelS}

Twenty-first century learning must be relevant, engaging, effective and learner-centric (Vockley and P21, 2007). It is therefore essential to replace outmoded 'closed classroom' models of teaching and learning, which emphasize delivery of information by an instructor and/or from a textbook, with new more learner-centric models (McLoughlin and Lee 2008a, p. 641). Tailoring learning pathways to the characteristics and aspirations of individual learners will undoubtedly demand significant organizational changes in schools (Furlong and Davies, 2012; ISC-I, 2004).

Other critical changes include a greater emphasis on learners taking responsibility for their own learning and the development of education systems that nurture such responsibility (Davies, Fidler and Gorbis, 2011; Facer, 2011). Research has shown that learners' attitudes, ownership of learning and level of independence are all affected when they take responsibility for their learning (Meyer et al., 2008). Adapting education to the needs of the twenty-first century learner means adopting a flexible curriculum and provide learning that is individualized and self-regulated. This places additional demands on learners to make the right choices (Ericsson AB, 2012) and on teachers to facilitate learner autonomy and independence. Teachers must become comfortable with managing new forms of classroom dynamics and supporting multiple teams of students working independently, as they explore and gain new understandings and skills to prepare them for twenty-first century life (Trilling and Fadel, 2009)

\section{ENCOURAGE LIFELONG LEARNING}

There is growing awareness that lifelong learning embodies the philosophy, conceptual framework and organizing principle for education in the twenty-first century, with the idea of learning for empowerment at its centre. UNESCO-ERF (2013) emphasizes the importance of advocating a 'lifelong learning framework that creates comprehensive and flexible pathways combining formal, non-formal and informal learning opportunities to accommodate differences in learning needs'. Megatrends such as slowing population growth, the ageing global population, continuing threats from climate change and the eastward shift in global markets all have an impact on current learning and the level of relearning called for in future years. Ease of access to mobile technologies and the rapid assimilation of mobile communications into the lives of those aged 25 years and under have increased the availability of continuous learning.

This trend has the potential to transform the ways in which today's learners contend with the complex problems ahead (Brown, 2005; Underwood, 2007). Carneiro (2007) notes that people will face meta- 
learning challenges throughout their lives. They will likely include learning to organize multiple sources of information, learning to learn from experience and deal with the social dimensions of knowledge formation, learning to self-regulate time and effort to learn, learning to forget and to unlearn whenever necessary, and learning to make room for new knowledge. The ready availability of lifelong learning will provide pathways to learning only imagined before. In the future, learners of all ages will be able to access knowledge needed to solve simple or complex problems as they appear without the need to enroll in formal degree programmes, leave their jobs to attend school, or spend considerable sums of money to upgrade their skills. Indeed, perceptions about the value of education are expected to change as lifelong learning makes access to education much easier and people's dreams of achievement are progressively realized (Carneiro, 2007; P21, 2013).

Facer (2012) and Redeck and Punie (2013) raise another concern that warrants consideration that of demographic change and the need for effective lifelong learning programmes and retraining options for workers with outdated or mismatched skills or who are seeking to retrain in a different field. In addition to the technological changes and advances mentioned hitherto, private industry will also become a key player in the provision of lifelong learning opportunities.

\subsection{Peer Culture and Children's Interactions: A Literature Review}

This section discussed the theoretical positions that offered support for the study as well as the relevant literature that has looked at collaboration in peer culture and the interactions that arise from children's participation in this culture. The study synthesized the developmental theories that offer explanations for why children cognitively and socially excel from their peer interactions as well as the importance of peer collaboration in the lives of young children. The literature discussed previous systematic observations of peer groups and children's interactions within these groups.

\subsection{Theoretical Underpinnings}

Constructivist theories as well as the sociocultural theory of Vygotsky reinforce the impacts of children's participation in peer interactions. Corsaro and Rizzo (1988) discussed constructivism as an interpretive approach to childhood socialization. They emphasized that the approach stresses children's active role in their development. Children's activities are always embedded in a social context and involve children's use of language and interpretive abilities. Children interpret, organize, and use information from the environment, and use the knowledge they gain from these actions to acquire skills and knowledge. As they discover a world that is full of meaning through interactions with their peers, they help to shape and share in their own developmental experiences. Corsaro and Rizzo (1988) also emphasized the fact that children's participation in interactional routines contributes to their acquisition of language and understanding of culture. The interactions they participate in within their peer culture also help them to understand their personal culture in a clearer manner. This occurs because when children enter into a social system, they interact and negotiate with those in the system. For preschool children, this system can be the children in their peer groups. Together, the children establish understandings that then become fundamental social knowledge that they will continue to build upon, thereby increasing their understanding of the cultural milieu in which they exist. The constant dialogue between the children as they discuss and negotiate helps to strengthen their language skills. Finally, Corsaro and Rizzo (1988) stressed that children's interactions outside of their family, namely with their playmates, effect their development. When children create peer cultures, they transform their knowledge and practices into the knowledge and skills necessary to exist in society. This occurs through the constant dialogue, negotiation, and construction of experiences between the children within the interactions. The children are able to do this at a level between them that is different from interactions with adults and is more in tune with their needs.

Vygotsky argued that in order to determine the nature and path of development in children it is essential to examine the social environment where the development occurs (Tudge, 1992). He believed that children do not develop in isolation, but rather in a social matrix. This social matrix is formed by the interconnection of social relationships and interactions between the children. They are shaped by the social organization of the society as a whole in which children exist (Nicolopoulou, 1993). Through these relationships and interactions, children collaborate towards a shared goal. As they work together, their culture is transmitted throughout the group through constant communication. Children use their actions and language as communication devices during their collaborations. The 
various constructs that make up each individual child's culture are expressed and shared between the children as they discuss and contribute to each other's ideas. The children are bound as a group through their identity and union, and the sociocultural meanings that are expressed by the children contribute to each child's identity and character. Together the children carry out collective representations which lead to cognitive and social advancement in the children (Nicolopoulou, 1993).

These representations consist of collaboration between the children using materials and conversations. As the children coordinate ideas, they are able to contribute to their present understanding of the situation and the information that is related to it cognitively and socially. Vygotsky argued that cognitive development not only takes place with social support from others in an interaction, but also involves the development of skill with socially developed tools for mediating intellectual activity. Skill is developed using cultural tools such as language through participation and communication. He argued that cognitive and social processes correspond in interactions due to the derivation of individual cognitive processes within the social interaction (Rogoff, 1993). The social environment is a major contributor to the cognition of children because of the open area of communication that exists between them that allows them to express and negotiate ideas as well as contribute to each other's understanding.

\subsection{The Role of Collaboration}

Vygotsky believed that children reconstruct their understanding of the world in a social manner through collaborative processes with their peers. He attributed the benefits of collaboration to the mutual involvement by the children, the equality of the relationship between the children when in a collective group, and the motivation of children to collaborate based on their shared understandings (Tudge, 1992). In particular, when children of mixed knowledge levels interact in collaboration, they are able to communicate on a level that they are able to understand and share with each other. Vygotsky labeled language "a powerful and strong tool" in children's interactions because of the shared meanings that form between children as well as the important transmission of social meanings (Tudge, 1992). Within the importance of language, Vygotsky recognized the importance of feedback between the children to promote a high level of joint understanding. As the children listen to and respond to each other's ideas and contributions to the interaction, they are able to reinforce their understandings, thereby extending their cognitive abilities. Therefore, the feedback contributes to cognitive comprehension because of the joint understanding between the children (Tudge \& Winterhoff, 1993).

Vygotsky argued that every function for a child occurs first on a social level and then on an individual level (Corsaro \& Rizzo, 1988). The language between the children as well as in each individual child moves through the same process. Language begins as social between the children, labeled social speech; then they will talk to themselves about the activity, labeled egocentric speech; and last they will have inner speech and thought about the process of the activity, labeled inner speech (Tenzer, 1990). Within these levels of speech exist a higher thought process in the children that represents their individual increasing capacity to organize and order thoughts in an active exchange with the environment (Tenzer, 1990). These speech activities further emphasize the importance of language in the communication between children in their interactions.

\subsection{The Role of Inter-subjectivity}

Vygotsky also believed that collaboration was only likely to be successful to the extent to which intersubjectivity was attained by the collaborating partners (Tudge \& Winterhoff, 1993)). Intersubjectivity is created between children when they are able to come to a shared understanding of the process and goals of the activity. Inter-subjectivity is ideally constructed when the children adopt each other's perspectives and transfer their ideas successfully through verbal and non-verbal communication. This requires a joint focus of attention (Goucu, 1993). This shared focus of attention is a part of a joint activity between children as they expand their existing knowledge and learn to understand new situations (Goucu, 1993). This is done through constant communication and reciprocation of each other's ideas. In a sense, the children come to a "cooperative understanding" within the interaction (Rogoff \& Tudge, 1999). They negotiate their ideas and experiences and use their knowledge of the situation to contribute to the interaction. Trust between the children is important in the formation of intersubjectivity as well as their combined faith in the mutually shared 
world in which they are in when they are interacting (Goucu, 1993). These aspects of the interaction increase the bond and therefore the understanding between the children.

Children can attain intersubjectivity in their collaborations in at least three different ways. They can attain it by converging different meanings until all of the children's understandings of the task agree; when one child assumes the view of the other child; or when the children mutually shift between the two views and come to a joint understanding (Stremmel \& Fu, 1993). Intersubjectivity between children during their collaborations enhances the experience and allows the children to communicate on a shared level.

\subsection{The Zone of Proximal Development}

Vygotsky also emphasized certain areas of children's interactions that specifically contribute to a higher level of cognitive understanding. One area in children that is specifically involved in increased understanding is the "zone of proximal development". Vygotsky defined the zone of proximal development as "the distance between the actual developmental level as determined by independent problem solving and the level of potential development as determined through problem solving under adult guidance or in collaboration with more capable peers" (Vygotsky, 1978). This zone defines the functions that have not yet matured in children but are in the maturation process. Without the children interacting and communicating, their zone of proximal development would not be effected. When children assist each other in higher levels of learning as well as how to structure and manage their own learning, they are working in the zone of proximal development. Working in this area with peers gives children an opportunity to perform at levels they cannot achieve on their own (Stremmel \& Fu, 1993).

Because of the importance of interaction within the zone to increase levels of cognitive understanding, it is present in many aspects of children's interactions. Children teach each other in structured interactions, thereby shaping and directing their cognition. They teach each other through the behaviors of scaffolding and modeling. When children scaffold each other, they use their knowledge of the situation to assist each other in the specific skill of the activity. This "graduated assistance" simplifies the task for a less capable child and allows them to master the specific skill with help (Tharpe \& Gallimore, 1988). When children model, they offer each other behavior for imitation. As children guide each other through an activity towards a specific goal, they exhibit behaviors that assist each other towards a higher understanding of the activity as well as step further towards the mastery of a skill (Tharpe \& Gallimore, 1988). Children's culture continues to play a key role in their interactions, thereby affecting the zone of proximal development. Children transmit their understanding of their culture and use the contributions of others to better understand that culture in the context of the group. Culture can be considered a guide, further emphasizing the fact that the social world guides and stimulates the involved children's development (Nicolopoulou, 1993). The stimulation of the social interaction allows the children to advance to higher understanding of the cognitive world they are exploring through their social interaction.

\subsection{Assisted Performance}

Tharpe and Gallimore (1988) utilized Vygotsky's ideas to stress the need for education to move towards a more collaborative role between students and teachers. They argued that teaching must be redefined as "assisted performance," where teachers assist the children by providing structure and assistance in their work. Assisted performance also occurs between children when they participate in experiences together by providing information to each other that increases their understanding of the activity. This concept is related to Vygotsky's term of working within the zone of proximal development. Vygotsky (1978) believed that teaching and learning is best when it proceeds ahead of development because it "awakens and rouses to life the functions that are in the stage of maturing." These functions lie in the zone of proximal development and can be created for any domain of skill. When teaching is structured under the concept of assisted performance, it works within the zone at points where children's performance requires assistance. Assistance is best offered in interactional contexts where there is the possibility of generating joint performance. Within a joint performance between children on a task, scaffolding can occur. Tharpe and Gallimore (1988) called scaffolding "the idea role of a teacher." Scaffolding is similar to behavior shaping but does not involve simplifying a task, but rather holds the task difficulty constant while simplifying the child's role in the 
task. The adult or more capable peer simplifies the other child's role by means of graduated assistance, thereby working to help the child mature those skills to a point where they can perform the task on their own. This form of "natural teaching" involves interactions that awaken and arouse the children's mind, communication, and expression to a point where they can acquire the desired skill with the assistance.

\section{CONCLUDING REMARKS AND EMERGING ISSUES FOR CONSIDERATION}

This paper addresses the many possible futures and forms of learning in the digital age and the pedagogies that support learners in acquiring new competencies and skills to tackle twenty-first century challenges. Education should prepare learners to tackle collaborative problem-solving scenarios that are persistent and lack clear solutions. Real-world challenges are highly complex, often ill-defined and interdisciplinary in nature, spanning multiple domains (social, economic, political, environmental, legal and ethical). Learners must have opportunities to reflect on their ideas, hone their analytical skills, strengthen their critical and creative thinking capacities, and demonstrate initiative. In particular, the ability to evaluate new inputs and perspectives, build new capacities and strengthen autonomy will be crucial.

Many factors are driving change in the ways that learners are educated. Pressures may vary from nation to nation, but the message is fundamentally the same: education is failing to prepare learners for the challenges ahead. Students are not learning under the current system of education and are being short-changed. Learners are missing out on experiences that will prepare them for more satisfying lives and productive work. Nations are also losing opportunities to prepare youth for citizenship, and economies are suffering from a lack of innovation. The twenty-first century has immense potential to reaffirm the role of education with a view to equipping young and old learners to address complex societal, economic and environmental issues. The transformation from teacher-led learning to self-directed learning to self-determined learning will provide learners with a range of competencies and skills needed to succeed in modern global societies. Personalized and tailor-made instruction will help learners to reach their full potential. Learners will be better prepared to interact with their own communities, virtually and in person, and to deal confidently with people from different cultures, while continuing to learn throughout their lives.

The increased tempo at which new developments are emerging will demand that young people quickly recognize the importance of lifelong learning. Re-skilling and updating competencies will enable learners of all ages to adapt to new expectations in the twenty-first century workplace and life. Education providers must adopt curricula that are comprehensive yet flexible, and Centre on content that extends thinking and reasoning, so as to equip learners to tackle twenty-first century challenges and pressures. There is also a strong need for curricula that are open to learner input, interdisciplinary in focus, and effectively blend informal and formal learning. Pedagogy 2.0 approaches such as participation, collaborative learning, and personalized learning, teaching for transfer, project based learning and real-world contexts will be the key to stimulating such growth. The commitment of educators to lifelong learning, through ongoing professional development, professional learning communities and mentoring, will form the foundation of this new pedagogy. The next step is to combine all of these educational innovations and supports for the betterment of every student. Twenty-first century learners can expect to be part of a culture that values participation with ample opportunities to initiate, produce and share one's creations. They will be expected to communicate and collaborate in a variety of contexts, engage in peer-to-peer learning and develop as global citizens. Through applying learner-centered pedagogy such as problem, inquiry and project-based learning, students will gain insights, understanding, increased capacities and confidence, by grappling with real-world questions and problems. Approaches that lead learners to question their own beliefs and those of their peers will enhance reflection, metacognition and the construction of new knowledge. Networked education will enable learners to participate in more personalized and equitable learning opportunities, through collaboration with their own communities and teams of learners separated by time and distance.

The roles of schools in the future and their capacity to radically transform themselves remain uncertain. Nations must acknowledge the many reasons why twenty-first century learning must be different. They must critically evaluate traditional education to determine whether schools are living up to current expectations. Every nation has its own vision of what a twenty-first century education 
should look like. Innovations that produce successful learning in one nation can have a ripple effect as other nations adopt and adapt these methods for their own use. With increased international cooperation and collaboration, each nation can participate in building a global learning network as dominant and pervasive as existing international networks in business, finance and communications.

\section{REFERENCES}

[1] Ala-Mutka, K., Redecker, C., Punie, Y., Ferrari, A., Cachia, R. and Centeno, C. 2010. The Future of Learning: European Teachers' Visions. JRC Scientific and Technical Reports. Luxembourg, Publications Office of the European Union. http://ftp.jrc.es/EURdoc/JRC59775_TN.pdf (Accessed 22 June 2014).

[2] Anderson, A. 2014. Southern perspectives on learning and equity in the post-2015 sustainable development agenda. The Brookings Institution (online). www.brookings.edu/blogs/ education-plusdevelopment/posts/2014/01/15-sustainabledevelopment- agenda-anderson (Accessed 28 June 2014).

[3] Barkely, E.F., Cross, K.P. and Howell Major, C. 2014. Collaborative Learning Techniques: A Handbook for College Faculty. 2nd edn. San Francisco, Jossey-Bass.

[4] Barron, B. and Darling-Hammond, L. 2008. Teaching for meaningful learning: a review of research on inquiry-based and cooperative learning. L. Darling-Hammond, B. Barron, P.D. Pearson, A.H. Schoenfeld, E.K. Stage, T.D. Zimmerman, G.N. Cervetti and J.L. Tilson (eds), Powerful Learning: What We Know About Teaching for Understanding. San Francisco, Calif.,

[5] Bates, A.W. 2011. Understanding Web 2.0 and its implications for e-learning. M. Lee and C. McLoughlin (eds), Web 2.0-Based E-Learning: Applying Social Informatics for Tertiary Teaching.

[6] Beetham, H. and Sharpe, R. (eds). 2013. Rethinking Pedagogy for a Digital Age. 2nd edn. New York, Routledge.I

[7] Ben-David Kolikant, Y. 2010. Digital natives, better learners? Students' beliefs about how the Internet influenced their ability to learn. Computers in Human Behavior, Vol. 26, pp. 1384-1391. http://cyber.law.harvard.edu/communia2010/

[8] Bolstad, R. 2011. Taking a 'Future Focus' in Education - What Does It Mean? NZCER Working Paper. Wellington, New Zealand Council for Educational Research. www.nzcer. org.nz/ system/files/takingfuture-focus-in-education.pdf (Accessed 8 March 2014).

[9] Cullen, J. 2013. Our schools are stuck - the gap between educational policy and reality: why schools are stuck and need to change. MENON Network Policy Brief, No. 3, pp. 1-9. www.menon.org/wpcontent/uploads/2013/04/MENONPolicy- brief-3-Apr-2013.pdf (Accessed 27 February 2014).

[10] Davidson, C.N. and Goldberg, D.T. with the assistance of Jones, Z.M. 2009. The Future of Learning Institutions in a Digital Age. MacArthur Foundation Reports on Digital Media and

[11] Davies, A., Fidler, D. and Gorbis, M. 2011. Future Work Skills 2020. Palo Alto, Calif., University of Phoenix Research Institute. www.iftf.org/ uploads/media/SR-1382A_UPRI_future_work_skills_sm.pdf (Accessed 20 May 2014).

[12] Delors, J., Al Mufti, I., Amagi, I., Carneiro, R., Chiung, F., Geremek, B., Gorham, W., Kornhauser, A., Manley, M., Padrón Quero, M., Savané, M-A., Singh, K., Stavenhagen, R., Won Suhr, M. and Nanzhao, Z. 1996. Learning: The Treasure Within: Report to UNESCO of the International Commission on Education for the Twenty-First Century. Paris, UNESCO Publishing. http://plato.acadiau.ca/Courses/pols/conley/ QUEBEC98/DELORS 1/delorse.pdf (Accessed 18 February 2014).

[13] Hershey, Penn., Idea Group Inc. www.tonybates.ca/wpcontent/ uploads/Final-typeset-chapter1.pdf

[14] Johnson, L., Adams Becker, S., Estrada, V., Freeman, A., Kampylis, P., Vuorikari, R. and Punie, Y. 2014. Horizon Report Europe: 2014 Schools Edition. Luxembourg, Publications Office of the European Union/Austin, Texas, the New Media Consortium.

[15] Kerchner C.T. 2011. Learning 2.0: Time to Move Education Politics from Regulation to Capacity Building (online

[16] Redecker, C., Ala-Mutka, K., Leis, M., Leendertse, M., Punie, Y., Gijsbers, G., Kirschner, P., Stoyanov, S. and Hoogveld, B. 2011. The Future of Learning: Preparing for Change. Luxembourg, Publications Office of the European Union. http://ftp.jrc.es/EURdoc/JRC66836.pdf (Accessed 5 April 2014).

[17] Robinson, K. 2006. How schools kill creativity (online video). TED Conference 2006. Monterey, Calif. www.ted.com/talks/ken_robinson_says_scholos_kill_creativity (Accessed 15 February 2014).

[18] Saavedra, A. and Opfer, V. 2012. Teaching and Learning $21^{\text {st }}$ Century Skills: Lessons from the Learning Sciences. A Global Cities Education Network Report. New York, Asia

[19] Underwood, J.D.M. 2007. Rethinking the digital divide: impacts on student-tutor relationships. European Journal of Education, Vol. 42, No. 2, pp. 213-222. 
[20] Webb, N. M. (1995). Group collaboration in assessment: Multiple objectives, processes, and outcomes. Educational Evaluation and Policy Analysis, 17(2), 239-261.

[21] Webb, N. M., Nemer, K. M., Chizhik, A. W., \& Sugrue, B. (1998). Equity issues in collaborative group assessment: Group composition and performance. American Educational Research Journal, 35(4), 607651.

[22] Willingham, D. T. (2007). Critical thinking: Why is it so hard to teach? American Educator, 31(2), 8-19.

[23] Saner, H., McCaffrey, D., Stecher, B., Klein, S., \& Bell, R. (1994). The effects of working in pairs in science performance assessments. Educational Assessment, 2(4), 325-338.

[24] Schraw, G., Crippen, K. J., \& Hartley, K. (2006). Promoting self-regulation in science education: Metacognition as part of a broader perspective on learning. Research in Science Education, 36, 111-139.

[25] Schraw, G. \& Moshman, D. (1995). Metacognitive theories. Educational Psychology Review, 7(4), 351371.

[26] Thayer-Bacon, B. J. (2000). Transforming critical thinking: Thinking constructively. New York: Teachers College Press.

[27] Tindal, G. \& Nolet, V. (1995). Curriculum-based measurement in middle and high schools: Critical thinking skills in content areas. Focus on Exceptional Children, 27(7), 1-22.

[28] Tudge, J. R. H. (1992). Processes and consequences of peer collaboration: A Vygotskian analysis. Child Development, 63(6), 1364-1379.

[29] Turner, J. C. (1995). The influence of classroom contexts on young children's motivation for literacy. Reading Research Quarterly, 30(3), 410-441.

[30] Van Boxtel, C., Van der Linden, J., \& Kanselaar, G. (2000). Collaborative learning tasks and the elaboration of conceptual knowledge. Learning and Instruction, 10(4), 311-330.

[31] Webb, N.M. (1991). Task-related verbal interaction and mathematical learning in small groups. Research in Mathematics Education, 22(5), 366-389.

[32] Webb, N. M. (1993). Collaborative group versus individual assessment in mathematics: Processes and outcomes. Educational Assessment, 1(2), 131-152.

\section{AUTHORS' BIOGRAPHY}

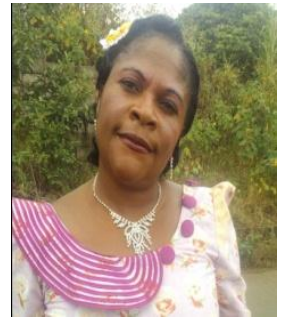

Dr. Kumncho Eveline Neh is a lecturer of educational psychology in the Department Of Educational Psychology, Faculty of Education, University Of Buea. She is a teacher trainer at Government Teacher Training College Limbe, Cameroon. Kumncho Eveline has a $\mathrm{PhD}$ in Educational Psychology with a Concentration in Developmental Psychology from the University of Buea, Cameroon. She has a Master's Degree (M.Ed) in Educational Psychology, a Bachelor's Degree (BE.d) in Curriculum Studies and Teaching with specialty in English Language. Dr. Kumncho Eveline Neh equally has a Teacher Grade One Certificate (CAPIEMP). Dr. Kumncho Eveline Neh is a renowned Researcher in areas such as: teacher education: inclusive education: cultural dynamics that shape socialization, parenting, learning and development etc. She is a registered member of the Global Research Network with REG. No: 12776008RKL. Dr. Kumncho Eveline Neh is a researcher with great potentials working with "Lukong Research Foundation" a research organization aimed at building mutual-help, Equal Participation, Accessible Society with Love and care through the Utilization of Available Resources in Building up an Inclusive Rehabilitation Platform which promotes the Equal Participation of people with disabilities and enhances Community Development and research activities. Dr. Kumncho is a Research Consultant and a Developmental Psychologist.

Citation: Dr. Kumncho Eveline Neh. "Peer Collaborative Interactions: Implications for Enhancing Creativity and Innovation among Learners in Cameroon" International Journal of Humanities Social Sciences and Education (IJHSSE), vol 5, no. 8, 2018, pp. 43-53. doi: http://dx.doi.org/10. 20 431/2349-0381.0508007.

Copyright: (c) 2018 Authors. This is an open-access article distributed under the terms of the Creative Commons Attribution License, which permits unrestricted use, distribution, and reproduction in any medium, provided the original author and source are credited. 